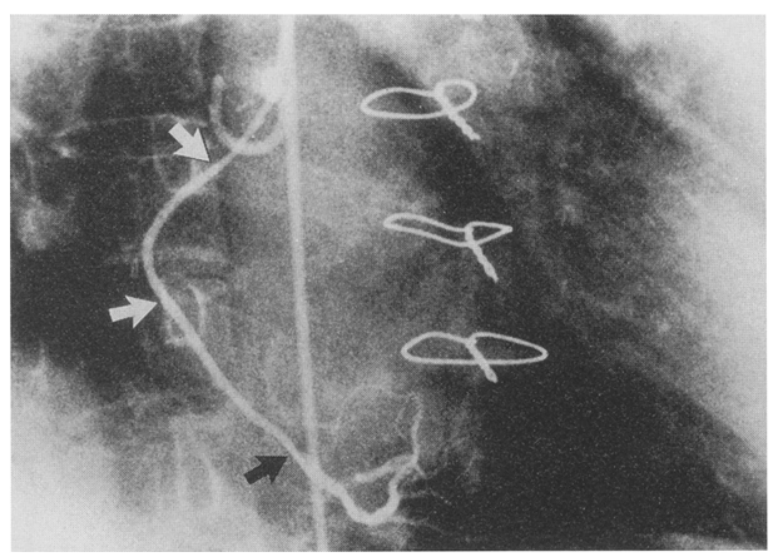

Fig. 2. Postoperative angiogram showed that the descending branch of the LFCA bypass graft was patent (arrows).

CABG was performed per protocol. The distal portion of the descending branch of the LFCA was first anastomosed to the right coronary artery and the proximal portion to the ascending aorta. The distal portion of the LITA was then anastomosed to the left anterior descending artery. The flow rate within the descending branch of the LFCA graft was $40 \mathrm{ml} / \mathrm{min}$ when the patient was weaned from cardiopulmonary bypass.

The patient recovered without complications and regained full use of the left lower extremity. A postoperative coronary arteriogram of the descending branch of the LFCA and LITA grafts and native vessels was obtained at 30 days. This angiogram showed that the descending branch of the LFCA bypass graft was patent and functional (Fig. 2). Electrocardiography showed no ST change during exercise.
Several points regarding this use of the descending branch of the LFCA as a bypass graft can be addressed. With regard to the quality of the vessel, the descending branch of the LFCA of this particular patient, although thin, was similar in size to the LITA. With the free internal thoracic artery already applied as a graft, ${ }^{4}$ the free descending branch of the LFCA can be considered as an alternative. Moreover, the descending branch of the LFCA is readily accessible and easier to isolate than the internal thoracic artery, gastroepiploic artery, inferior epigastric artery, and radial artery. Last, inasmuch as the muscles of the thigh supplied by the descending branch of the LFCA have a rich collateral supply, functional deficits associated with the operation are potentially lessened. For these reasons, we believe that the descending branch of the LFCA shows promise as an autologous graft for $\mathrm{CABG}$.

We thank Michelle Zimmerman for help with manuscript preparation.

\section{REFERENCES}

1. Song YG, Chen GZ, Song YL. The free thigh flap: a new free flap concept based on the septocutaneous artery. Br J Plast Surg 1984;37:149-59.

2. Koshima I, Fukuda H, Yamamoto H, Moriguchi T, Sọeda S, Ohta S. Free anterolateral thigh flaps for reconstruction of head and neck defects. Plast Reconstr Surg 1993;92:421-8.

3. Koshima I, Kawada S, Etoh H, Kawamura S, Moriguchi T, Sonoh $\mathrm{H}$. Flow-through anterior thigh flaps for one-stage reconstruction of soft-tissue defects and revascularization of ischemic extremities. Plast Reconstr Surg 1995;95:252-60.

4. Loop FD, Lytle BW, Cosgrove DM, Golding LAR, Taylor PC, Stewart RW. Free (aorta-coronary) internal mammary artery graft. J Thorac Cardiovsc Surg 1986;92:827-31.

\title{
CYTOMEGALOVIRUS PNEUMONIA AFTER CARDIOVASCULAR OPERATIONS
}

\author{
N. Fukushima, MD, ${ }^{\text {a }}$ R. Shirakura, MD, ${ }^{\mathrm{a}}$ N. Taenaka, MD, ${ }^{\mathrm{b}} \mathrm{S}$. Nakano, MD, ${ }^{\mathrm{a}}$ and H. Matsuda, MD, ${ }^{\mathrm{a}}$ Osaka, Japan
}

Cytomegalovirus (CMV) has long been known to be fatal to immunocompromised patients. It has been widely recognized that patients undergoing cardiovascular oper-

From the First Department of Surgery, ${ }^{a}$ Department of Intensive

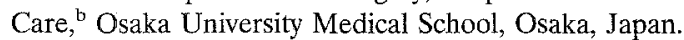

Received for publication Oct. 27, 1995; accepted for publication Oct. 30, 1995.

Address for reprints: Norihide Fukushima, MD, First Department of Surgery, Osaka University Medical School, 2-2 Yamada-Oka, Suita, Osaka 565, Japan.

J Thorac Cardiovase Surg 1996;112:547-8

Copyright $(\mathcal{C} 1996$ by Mosby-Year Book, Inc.

$0022-5223 / 96 \$ 5.00+0 \quad \mathbf{1 2} / \mathbf{5 4} / \mathbf{7 0 3 3 3}$ ations, especially open heart operations, are susceptible to CMV infection. ${ }^{1}$ The majority of these infections, however, are subclinical and only a small percent of these individuals have a more severe illness characterized by fever and liver injury. ${ }^{2}$ Thus CMV infection after cardiac operations has not been considered a serious disease for a long time. However, recent reports have emphasized that CMV infection after heart operations may be far more sinister. ${ }^{2,3}$ In this report, we describe two cases of multiple organ failure and CMV pneumonia after cardiovascular operation. We also discuss the methods of diagnosis and treatment for CMV infection.

CASE 1. A 47-year-old woman underwent open mitral commissurotomy and tricuspid annuloplasty. The CMV titer was 1:256 before the operation. She had aspiration 
pneumonia on the second postoperative day, which necessitated extracorporeal membrane oxygenation. She was treated successfully and weaned from extracorporeal membrane oxygenation on the sixth postoperative day, with an increase in arterial oxygen pressure $\left(\mathrm{PaO}_{2}\right) . \mathrm{PaO}_{2}$ decreased again, however, and the chest $\mathrm{x}$-ray film showed interstitial pneumonitis in both lungs on the tenth postoperative day. Polymerase chain reaction (PCR) test ${ }^{4}$ for $\mathrm{CMV}$ in the bronchoalveolar lavage specimen and the blood yielded a CMV-positive result on the eleventh postoperative day. Hyper-CMV immune globulin (polyglobulin) in a dose of $500 \mathrm{mg} /$ day and ganciclovir in a dose of $2.5 \mathrm{mg} / \mathrm{kg}$ per day were given intravenously for 3 and 14 days, respectively. Findings of interstitial pneumonitis in the chest $x$-ray film almost disappeared, and $\mathrm{PaO}_{2}$ increased from 180 to $540 \mathrm{~mm} \mathrm{Hg}$ at an inspired oxygen fraction of 1.0. PCR and culture for CMV in the blood yielded CMV-negative results. She was weaned from a respirator on postoperative day 22 , but she died of multiple organ failure combined with systemic Serratia infection on POD 101.

CASE 2. A 51-year-old woman underwent aortic valve replacement, open mitral commissurotomy, tricuspid annuloplasty, and left atrial plication. Delayed sternal closure was done. The CMV titer was 1:512 before the operation. She underwent intraaortic balloon pumping and continuous venovenous hemodialysis and had sepsis as a result of methicillin-resistant Staphylococcus aureus. The chest $x$-ray film showed interstitial pneumonitis in both lungs on postoperative day 22, and $\mathrm{PaO}_{2}$ was decreasing. PCR for CMV virus of the bronchoalveolar lavage specimen and the blood yielded CMV-positive results on postoperative day 22. Polyglobulin and ganciclovir were given in the same doses as in case 1 . Findings of interstitial pneumonitis in both lungs became unremarkable and $\mathrm{PaO}_{2}$ increased. Although PCR yielded CMVnegative results on postoperative day 42, $\mathrm{PaO}_{2}$ decreased again and the woman died of multiple organ failure combined with systemic Serratia infection on the postoperative day 43.

Comments. CMV infection has not been considered to be severe in individuals not affected by immunocompromise, including patients having cardiothoracic operations. ${ }^{1}$ However, it has been reported recently that even previously healthy adults may also contract severe CMV infection, such as CMV pneumonia. ${ }^{5}$ Moreover, recent reports indicated the possibility that patients might manifest severe CMV infection after heart operations. ${ }^{2,3}$ In the present report, two patients who had not been immunocompromised and CMV seropositive before their operations had CMV pneumonia after cardiovascular operations, and both died of multiple organ failure even though CMV culture of the blood became negative. Thus CMV infection should be considered to be a much more severe illness, even in patients who are not immunocompromised.

The presence of CMV in bronchoalveolar lavage specimen or blood is not in itself definitive evidence of CMV diseases, because it is important to distinguish between CMV infection resulting from viral reactivation and $\mathrm{CMV}$ disease itself, that is, CMV pneumonia. Before the present study, PCR tests for CMV were done in 20 normal subjects and 26 nonimmunocompromised cardiovascular patients with positive CMV antibody titer, but none had positive PCR results for CMV. PCR tests and culture for CMV were done in 10 patients with interstitial pneumonia after cardiac operations. The present two patients had CMV-positive results, whereas the remaining eight patients had CMV-negative results. Therefore our method for PCR is a highly specific means of diagnosing CMVrelated disease.

In conclusion, the present study demonstrates that severe CMV infection, such as CMV pneumonia, can occur in patients having cardiac operations. If interstitial pneumonia is suspected, CMV infection should be sought as soon as possible, even in patients who were not immunocompromised before the operation or who were seropositive for CMV.

\section{REFERENCES}

1. Endresen K, Gjesdal K, Orstavik I, et al. Primary Cytomegalovirus infection following open heart surgery. Acta Med Scand 1985;218:423-8.

2. Domart Y, Trouillet JL, Fagon JY, et al. Incidence and morbidity of cytomegaloviral infection in patients with mediastinitis following cardiac surgery. Chest 1990;97:18-22.

3. Vander Salm TJ. Cytomegalovirus: More dangerous to the cardiac surgical patient than we thought? Chest 1990;97:3-4.

4. Demmler GD, Buffone GJ, Schimbor CM, May RA. Detection of cytomegalovirus in urine from newborns by using polymerase chain reaction DNA amplification. J Infect Dis 1989;158:1177-84.

5. Baumgartner JD, Glauser MP, Burgo-Black AL, et al. Severe cytomegalovirus infection in multiply transfused, splenectomised, trauma patients. Lancet 1982;2:63-6. 